\title{
Decentralized Composting of Vegetable Market Waste through Pit Composting: An Alternative for Urban City Waste
}

\author{
Rajiv Lochan Bikash Roy, Rejaoon Al Rejah, Kangkan Baruah, Rasna Saikia, and Surojit Dey
}

\begin{abstract}
Guwahati city, gateway to North-East India, is undergoing rapid urbanization due to which it experiences lack of landfill for municipal solid waste (MSW) disposal. The city generates 626 tons of waste daily including vegetable market waste that is dumped directly in the landfill without treatment. This generates not only greenhouse gas (GHG) emission and pollution but also leads to scarcity of land. In an attempt to reduce the volume of the waste at the source, at least the organic fraction, an experiment of composting has been carried out in the Assam down town University campus, Guwahati. The process of composting is done on a wooden pit by collecting the vegetable market waste from the nearby area of the University. The composting is made aerobic by inserting a perforated pipe through the pit. The composting process took several weeks to complete and another two to three weeks for curing of the manure. Test results of the manure revealed that it can be used in agricultural field for soil amendment.

Since pit composting requires very less space, the findings of this experiment suggest that if each vegetable market of the city sets up a small composting plant within the market or in a nearby area the problem of waste disposal can be minimized to a great extent.
\end{abstract}

Index Terms-Pit composting, market waste, natural aeration, $\mathrm{C} / \mathrm{N}$ ratio, aerobic, Guwahati.

\section{INTRODUCTION}

The solid waste generated from households, commercial establishments, hotel and restaurants, markets, school, institution and offices, street sweepings and drain clean and other sources viz. temples, parks, exhibition halls, marriage halls, hostels etc. are termed as municipal solid waste (MSW) and municipal bodies or other governmental authorities are responsible for its storage, transportation and treatment. The vegetable market, as suggested is generated from vegetable markets and it falls under MSW. Solid waste from industrial processes is generally not considered municipal waste. Municipal solid waste management is the management of generation, storage, collection, transfer and transport, processing and disposal of solid wastes in an environmentally compatible manner with due considerations of the principles of economy, aesthetics, energy and conservation [1]. Municipal solid waste is a potential resource of organic materials, which can be altered into compost or biogas or bio-fertilizer and some portion of the MSW can also be

Manuscript received April 30, 2016; revised November 21, 2016.

The authors are with the Department of Mechanical Engineering, Assam Down town University, India (e-mail: ralbi.roy@gmail.com). recycled and reused. Municipal solid waste (MSW) in Guwahati contains a large organic fraction around 78\% (Fig. 1) [2]. This organic fraction has the tendency to decompose which leads odor problems. The widely used technique for organic fraction is, "composting" and its result is the organic compost, which can be used as a manure and soil amendment on agricultural farms. The process is important, since it is a natural process and results in conservation of natural resources. If the organic fraction of the MSW is converted into compost then a very little amount left, the inorganic one which can be reused or recycled. This way the volume of the MSW discarded into the landfill can be minimized to great extent.

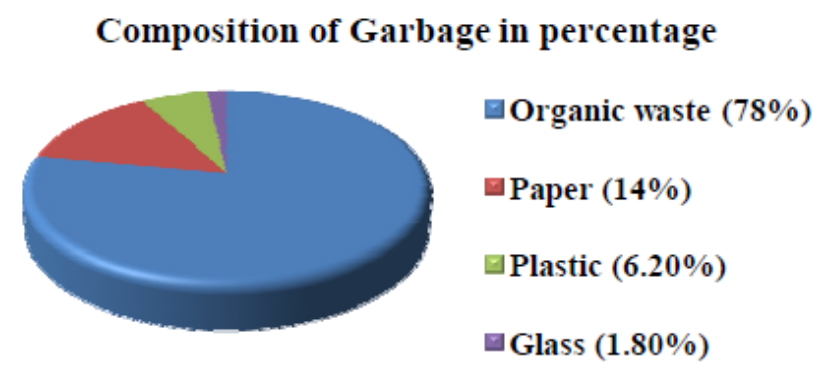

Source: City Development Plan, Guwahati adopted and recommended for approval of Ministry of Urban Development in 2006)

Fig. 1. Composition of waste generated in Guwahati city (\%).

Guwahati, the capital city of Assam (Fig. 2), India with latitude and longitude $26.1445^{\circ} \mathrm{N}, 91.7362^{\circ} \mathrm{E}$ is situated on the banks of the mighty river Brahmaputra with an area of $216 \mathrm{sq} \mathrm{km} \mathrm{[3].} \mathrm{The} \mathrm{city} \mathrm{is} \mathrm{formerly} \mathrm{known} \mathrm{as} \mathrm{Pragjyotishpura}$ in Sanskrit. It is the ancient urban area and the largest city of Assam. It is among the 100 fastest growing cities in the world and is often termed as the gateway of North East region. Recently it has been nominated as a potential smart city among the first 100 smart cities of India [4]. It is also called as "City of eastern light, the city of eastern astrology and the city of temples".

According to the latest census conducted in 2011, it has a population of 1.8 million with 3.2 lakhs households. The average populationdensity in this metropolis is about 6047 inhabitants per $\mathrm{km}^{2}$ [5]. The average waste generation in Guwahati city is $2.66 \mathrm{~kg}$ per day per household and markets, commercial establishments, hotels and restaurants, school and institutions, street sweeping and drain cleaning generate 129.6 tons waste/day [3]. Table I shows the different sources of waste generation in the city. Furthermore, these quantities are consistently rising day by day. This can be due to the rapid population growth, migration from rural areas, swelling 
of economic activities in the city and the lifestyle changes of the people. This augments not only scarcity of land for disposal of waste but also making municipal bodies difficult to process generated waste. But the city has the potential to generate approximately $30 \mathrm{MW}$ power from the solid wastes [6] and also the waste can be altered into useful compost.

TABLE I: SOURCES OF WASTE GENERATION IN GUWAHATI CITY SOURCE: DETAILED PROJECT REPORT (DPR) VOL. 2, GWMCPL, JANUARY 2008

\begin{tabular}{|c|l|l|}
\hline $\begin{array}{c}\text { Sl. } \\
\text { No. }\end{array}$ & \multicolumn{1}{|c|}{ Source } & No. of Units \\
\hline 1 & Domestic sources (Households) & 184,454 \\
\hline 2 & Commercial establishments & 38,871 \\
\hline 3 & Hotels and restaurants & 596 \\
\hline 4 & Markets & 14 \\
\hline 5 & Temples (Major) & 06 \\
\hline
\end{tabular}

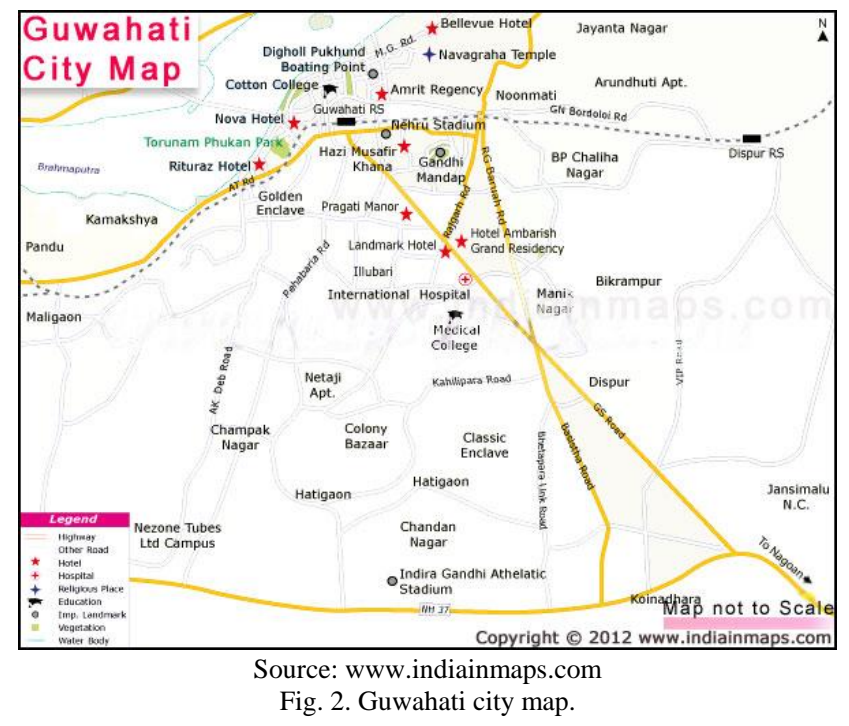

Guwahati Municipal Corporation (GMC) is responsible for waste collection, transportation and treatment of the waste of city. Unlike Dhaka and Chittagong city, Bangladesh, in Guwahati the waste separation at household is not common [7]. The waste is being collected from door to door and dumped into some secondary points situated different locations of the city. It has 778 secondary storage points at different locations [8]. From the secondary collection point the MSW is then disposed off to the landfill at Boragaon with compactor trucks. To do the job GMC let outs some private contractors on annual contracts and are paid according to the clearing of waste from the area assigned. If the GMC supervisor finds that the area allocated to the contractor has not been cleared then he has to pay a fine of three times of the fee he gets. GMC has its own fleet of 16trucks, which are being used for drain cleaning and on special occasions e.g. some festivals.

Guwahati city has few vegetable and fruit markets as compared to other commercial establishments and their contribution to total waste generated per day are very less. But whole amount of waste generated from these markets are biodegradable and it can be reduced at the source itself if treated tactfully. So, keeping this in mind, an experiment has been devised in the University campus in order to reduce this extra load on the landfill. For this experiment the waste is collected and taken to the campus from the nearby vegetable market.

\section{METHODOLOGY}

\section{A. Experimental Setup}

In the view of converting the organic waste generated in the fruit and vegetable market into useful manure through pit composting a pit is designed with wood. The reason behind making the pit by wood is the preparation cost is cheaper as compared to concrete and it is handy also and thereby the laboratory space can be utilized in some other purpose also while not in use. The dimension of the wooden pit is $2 \mathrm{~m} \times 1 \mathrm{~m}$ $\times 0.8 \mathrm{~m}(\mathrm{~L} \times \mathrm{W} \times \mathrm{H})$ as shown in the Fig. 3 . The dimension is chosen keeping in mind that in thermophilic stage of composting the desired temperature is achieved. A perforated pipe wrapped with a net is inserted through the pit so that the process gets sufficient amount of oxygen supply and aerobic biodegradation takes place. The bottom wall of the pit is sealed with cement so that the nutrition cannot seep away from the compost in the form of liquid.

TABLE II: WASTE DUMPING RECORD AND THEIR PHYSICAL CHARACTERISTIC

\begin{tabular}{|c|c|c|}
\hline Day & Quantity (kg) & \\
\hline Day 1 & 150 & \\
\cline { 1 - 2 } Day 2 & 106 & \multirow{2}{*}{ Cabbage leaves, brinjal, cauliflower, potato, tomato, onion \& garlic remains, banana leaves, chili and some fruit remains etc. } \\
\hline Day 3 & 97 & \\
\hline Total & $\mathbf{3 5 3}$ & \\
\end{tabular}

\section{B. Experimental Procedure}

After the pit became ready the vegetable waste is then collected from the Narengi daily market near the university and carried to the campus. The daily waste dumping record 
and physical characteristic of the waste is tabulated in Table II. Before dumping the waste is shredded into 2 to 3 inch size and some bulking agent viz. dry leaves, wood chips are added for proper oxygen supply and control oozing of leachate. The waste is mixed with dry leaves and wood chips in $4: 1$ ratio (by weight) to maintain the required $\mathrm{C} / \mathrm{N}$ ratio for faster decomposition. The temperature of the garbage is monitored and recorded daily. As the pit is full of waste it is kept under daily observation for two months. Whenever a sign of anaerobic decomposition is noticed the pile is turned and added some dry portion (saw dust) when needed.

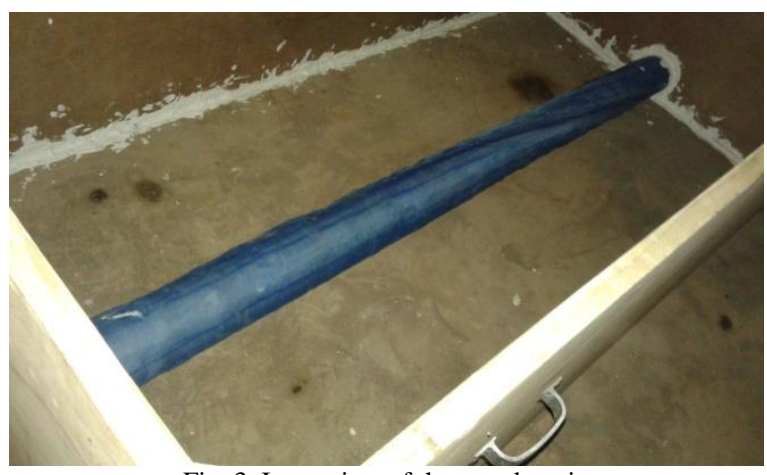

Fig. 3. Inner view of the wooden pit.

\section{RESULT AND DISCUSSION}

A total of $353 \mathrm{~kg}$ of vegetable waste dumped into the pit and left it to decompose for two months. The temperature was recorded up to 21 days as it reached room temperature.

Fig. 4 shows the temperature curve of the garbage pile. The maximum temperature reached by the pile was $650 \mathrm{C}$. It indicates the killing of pathogenic microorganism and weed seeds [9] and can be used as soil fertilizer.

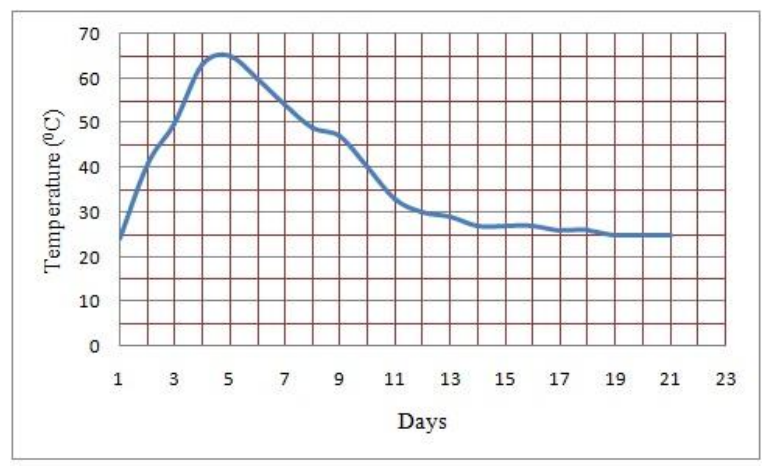

Fig. 4. Temperature curve of the garbage.

After two months the colour of the compost turns into hazy brown and the temperature stabilized. So, it was taken out of the pit and spread over the ground for curing (Fig. 5). The curing process continued for another one week. The compost was then became dark brown and smelled earthy. A sample of the compost was taken and tested in the laboratory. The test result is shown in Table III.

The chemical characteristics of the compost show it contains the primary plant nutrient viz. N, P and $\mathrm{K}$ in a fair quantity. The secondary nutrients are also present in enough amounts to use it as manure in the agricultural field.

In the final compost an interesting result was observed that all the waste components were decomposed totally except the banana leaves. It got dried only. This could be due to high fiber content in the leaves. So, the resultant compost was screened out the dried leaves and other dried fractions.

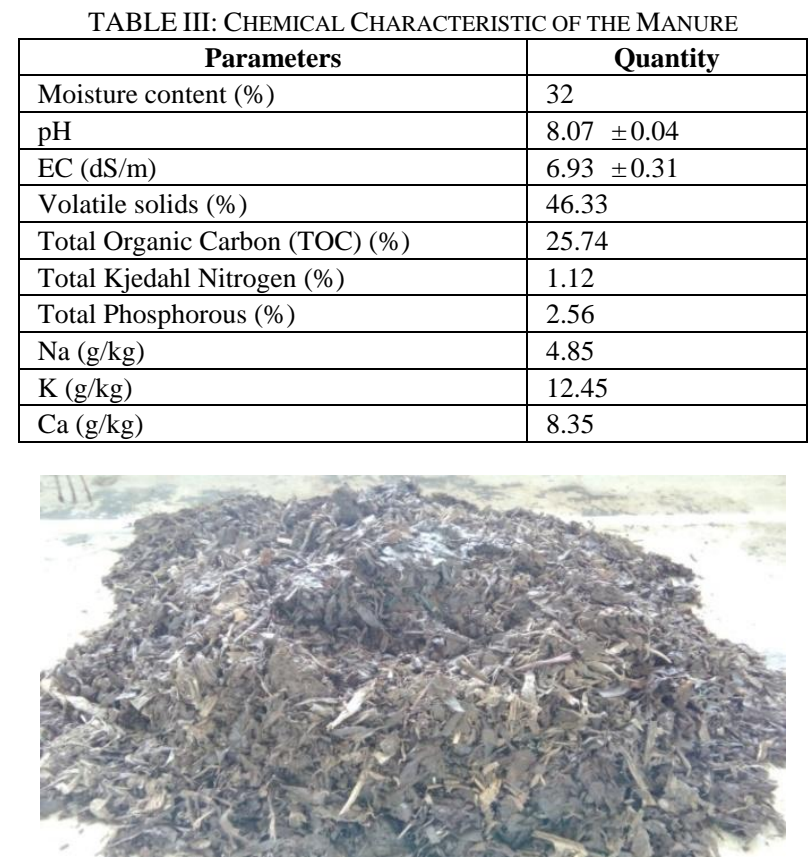

Fig. 5. Curing stage.

\section{CONCLUSION}

According to Ministry of Urban Development department, Government of India, there will be a demand of 35 MMT of chemical fertilizer (nutrients) in addition to $10 \mathrm{MMT}$ of organic and bio-fertilizer by 2025. Currently the country can be able to produce 5-6 MMT of NPK nutrients only (ref: urban dev.). So, there will be a vast gap between the availability and production capacity. This gap can be reduced by converting the organic fraction of the waste of all the cities into useful manure.

There are fourteen vegetable markets in Guwahati city and generated waste is being dumped directly into the landfill. Since Pit composting requires less area as compared to windrow composting, each market can set up a compost plant within their premises or an area in the vicinity and start altering the waste into manure through pit composting. This will not only reduce the volume of waste in landfill but also can contribute towards the requirement of bio-fertilizer of the country. Using an appropriate composting technology in combination with a sound financial management, as well as an appropriate marketing strategy ensures high quality compost and constant sales throughout the year [10]. The market authority will also be able to get extra revenue in selling the manure and maintain the plant.

\section{ACKNOWLEDGEMENT}

At the outset we extend our heartiest gratitude to the University authority for providing us the space for conducting the experiments and allowing us to do so in the campus. We are also very thankful to our students for helping us in collecting the waste from the Narengi daily market. Finally, our sincere thank is extended to the market authority for allowing us to take waste out from the market. 


\section{REFERENCES}

[1] Human Settlements Management Institute, New Delhi/WMC of UIFW, "City wide best practices in solid waste management in collection, transportation and disposal," Sep. 1997.

[2] City Development Plan, "Guwahati adopted and recommended for approval of Ministry of Urban Development in 2006".

[3] L. Gogoi, "Municipal solid waste disposal: A case study in Guwahati city to mitigate the manmade disaster," IOSR Journal of Humanities and Social Science, vol. 9, no. 3, Mar.-Apr., 2013.

[4] India TV News Desk. [Online]. Available: http://www.indiatvnews.com/news/india/know-all-100-upcomingsmar t-cities-of-india-50276. html

[5] Census of India 2011. (2011). Census report of Govt. of India, New Delhi.

[6] P. K. Pradhan et al., "Urban solid waste management of Guwahati city in north-east India," Journal of Urban and Environmental Engineering, vol. 6 , no. 2, pp. 67-73, 2012.

[7] A. U. Rahman et al., "A proposal for integrated market waste management in Bangladesh," International Journal of Engineering and Innovative Technology, vol. 1, no. 1, pp. 49-55, January 2012.
[8] Detailed project report (DPR), Guwahati Waste Management Company Private Ltd., January 2008.

[9] L. Cooperband, "The art and science of composting science of composting: A resource for farmers and compost producers," Center for Integrated Agricultural Systems, University of Wisconsin-Madison, March 29, 2002.

[10] C. Zurbrugg et al., "Decentralised composting in Bangladesh,a win-win situation for all stakeholders," Resources, Conservation and Recycling, no. 43, pp. 281-292, 2005.

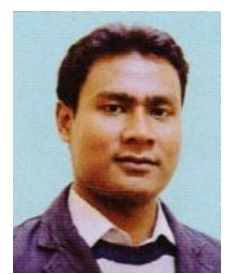

Rajiv LochanBikash Roy was born on Aug. 14, 1983 in Dhubri, India. He got the $\mathrm{BE}$ in mechanical engineering and the $\mathrm{M}$ Tech in computational seismology. He is an assistant professor in Dept. of Mechanical Engineering, Assam down town University, India. He was a site engineer in Evergreen Environmental Technology Pte. Ltd., Singapore for 1 year and a site geophysicist in Shiv-Vani Oil \& Gas Exploration Services Pvt. Ltd., India for 1 year. 